\title{
Introduction for the Column: New Developments and Resources in Technology for Behavioral Science
}

\author{
Jack Tsai ${ }^{1,2}$ (D) \\ Published online: 19 November 2020 \\ (C) This is a U.S. government work and not under copyright protection in the U.S.; foreign copyright protection may apply 2020
}

\section{Introduction}

This introduction is to remind readers about the purpose of this column and to discuss how it may be relevant to readers and their work. The COVID-19 pandemic has accelerated and elevated the need, our need, for technology in behavioral science in so many ways. During the pandemic, most healthcare institutions are relying on some form of virtual care or telehealth to address behavioral needs of the public. Many people are attending virtual conferences this year to receive the latest information about research and products in the field. The pandemic is a stress test on our systems of care, and the test has highlighted both our strengths but also our weaknesses. Many institutions have been amazingly adept at shifting to virtual forms of behavioral health care, but there are many areas such as connectivity, privacy, competency, and legal standards that need to be further developed. Where there is a need, there is opportunity! I am hopeful the pandemic, while a terrible and tragic event, may have a silver lining in spurring innovation and development. As much of my work is focused on addressing issues experienced by underserved populations, I would emphasize the need to be ensure that new behavioral technologies and virtual forms of care are accessible to all individuals and families, especially in low income and disability groups who may need care the most (Kim et al. 2018; Klee et al. 2016; Yamin et al. 2011).

This column "New Development and Resources in Technology for Behavioral Science" invites readers to get involved. There are so many new developments and resources in technology and behavioral science that it is difficult for the

Jack Tsai

jack.tsai@uth.tmc.edu

1 School of Public Health, University of Texas Health Science Center at Houston, Houston, TX, USA

2 U.S. Department of Veterans Affairs Central Office, National Center on Homeless Among Veterans, Homeless Programs Office, 7411 John Smith Drive, Suite 1100, San Antonio, TX 78240, USA average mental health professional to keep up, and that includes me as well. Thus, this column serves to provide some information about upcoming education and training events; new learning opportunities including articles, reports, and books to read about telehealth and behavioral technologies; and will occasionally feature interesting technological services and products. If any developers or companies have products they would like to share and can send sample products, I would welcome them to contact me. Material will be considered that encompasses the application of technology to all levels of behavioral health education (i.e., student, graduate, residents, faculty, clinicians, and community partners) and clinical care (e.g., translate technology into daily practice). The articles in this column are intended to be practical, offer options, and use technology to support dissemination and sustainability. I would also welcome readers who are interested in trying new products and writing about their user experiences to contact me as we can see about how to publish some of their experiences. Students and trainees who are interested in behavioral technologies are welcome and I am open to co-authoring columns. Certainly, this column will not be comprehensive and will not capture all technologies that are being developed, but at least we can strive to provide snapshots of recent developments and resources for readers to keep on their horizons.

\section{Upcoming Behavioral tech conferences in 2020}

The Technology, Mind and Society Showcase by the American Psychological Association

Virtual event

November 12-14, 2020

Description: The premier interdisciplinary showcase for emerging research and innovation on the critical role psychology plays in human and technology interaction.

Website: https://tms.apa.org/event/fe91267d-ca5f-404a8199-b3 fe 5e 841910/summary?environment=P2\&5S\% 2CM3\%2Cfe91267d-ca5f-404a-8199-b3fe5e841910= 


\section{Discover Teleshealth 2020}

November 4 and 6, 2020

Description: This event will feature leading authorities on telehealth as they bring to life real examples of telehealth being used in real communities that are impacting real people. Location: Great Wolf Lodge 150 Tom Hall Parkway LaGrange, GA 30240

Website: https://www.eventbrite.com/e/discover-telehealthconference-2020-tickets-65264698470

\section{SEARCH 2020 - The National Telehealth Research Symposium}

\section{Virtual Event}

November 12-13, 2020

Description: Will showcase connected health efforts, strategies, and partnerships, specifically those that focus on the research of telemedicine, telehealth, eHealth, mHealth, and other healthcare technologies.

Website: https://searchsociety.org/search2020-nationaltelehealth-research-symposium/

\section{Telehealth Secrets}

\section{October 5-7, 2020}

Description: How can you hack the 15-year healthcare adoption cycle? Can telehealth cure physician burnout? Telehealth Secrets is the one conference for healthcare innovators focused on driving business growth through virtual health.

Location: Santa Clara Marriott 2700 Mission College Boulevard, Santa Clara, California 95054 USA

Website: https://vsee.com/conference/

\section{International Conference on Biomedical and Telehealth January 11-12, 2021}

Description: This conference brings together academic scientists, researchers and research scholars to exchange and share their experiences and research results. It provides an interdisciplinary platform for researchers, practitioners and educators to present and discuss the most recent innovations, trends, and concerns as well as practical challenges encountered and solutions adopted in the fields of biomedical and telehealth.

Website: https://waset.org/biomedical-and-telehealthconference-in-january-2021-in-singapore

\section{National Telemedicine Summit \\ March 18-19, 2021}

Description: This conference creates an exciting, high level forum featuring knowledgeable leaders and executives from the nation's leading Hospitals and Health Systems who will share their perspectives, valuable insights and expertise on how to be best equipped for the rapidly evolving and exciting landscape of telehealth.

Website: https://www.wcforum.com/conferences/ telemedicine

\section{Selected Recent Publications}

Arevian, A. C., O’Hora, J., Rosser, J., Mango, J. D., Miklowitz, D. J., \& Wells, K. B. (2020). Patient and Provider Cocreation of Mobile Texting Apps to Support Behavioral Health: Usability Study. JMIR mHealth and uHealth, 8(7), e12655.

Carleton, K. E., Patel, U. B., Stein, D., Mou, D., Mallow, A., \& Blackmore, M. A. (2020). Enhancing the scalability of the collaborative care model for depression using mobile technology. Translational Behavioral Medicine, 10(3), 573-579.

Chow, P. I. (2020). Developing Mental or Behavioral Health Mobile Apps for Pilot Studies by Leveraging Survey Platforms: A Do-it-Yourself Process. JMIR mHealth and uHealth, 8(4), e15561.

Husebo, B. S., Heintz, H. L., Berge, L. I., Owoyemi, P., Rahman, A. T., \& Vahia, I. V. (2020). Sensing Technology to Facilitate Behavioral and Psychological Symptoms and to Monitor Treatment Response in People With Dementia. A Systematic Review. Frontiers in Pharmacology, 10, 1699.

Melia, R., Francis, K., Hickey, E., Bogue, J., Duggan, J., O’Sullivan, M., \& Young, K. (2020). Mobile health technology interventions for suicide prevention: systematic review. JMIR mHealth and uHealth, 8(1), e12516.

Taylor, C. B., Fitzsimmons-Craft, E. E., \& Graham, A. K. (2020). Digital technology can revolutionize mental health services delivery: The COVID-19 crisis as a catalyst for change. International Journal of Eating Disorders, 53(7), 1155-1157.

Torous, J., Myrick, K. J., Rauseo-Ricupero, N., \& Firth, J. (2020). Digital mental health and COVID-19: Using technology today to accelerate the curve on access and quality tomorrow. JMIR mental health, 7(3), e18848.

Queries about this column may be addressed to XXXX.XXX@XX.com

\section{References}

Kim, E. J., Yuan, Y., Liebschutz, J., Cabral, H., \& Kazis, L. (2018). Understanding the digital gap among us adults with disability: cross-sectional analysis of the health information national trends survey 2013. JMIR rehabilitation and assistive technologies, 5(1), e3.

Klee, A., Stacy, M., Rosenheck, R., Harkness, L., \& Tsai, J. (2016). Interest in technology-based therapies hampered by access: a survey of veterans with serious mental illnesses. Psychiatric Rehabilitation Journal, 39(2), 173-179.

Yamin, C. K., Emani, S., Williams, D. H., Lipsitz, S. R., Karson, A. S., Wald, J. S., \& Bates, D. W. (2011). The digital divide in adoption and use of a personal health record. Archives of Internal Medicine, 171(6), 568-574.

Publisher's Note Springer Nature remains neutral with regard to jurisdictional claims in published maps and institutional affiliations. 